
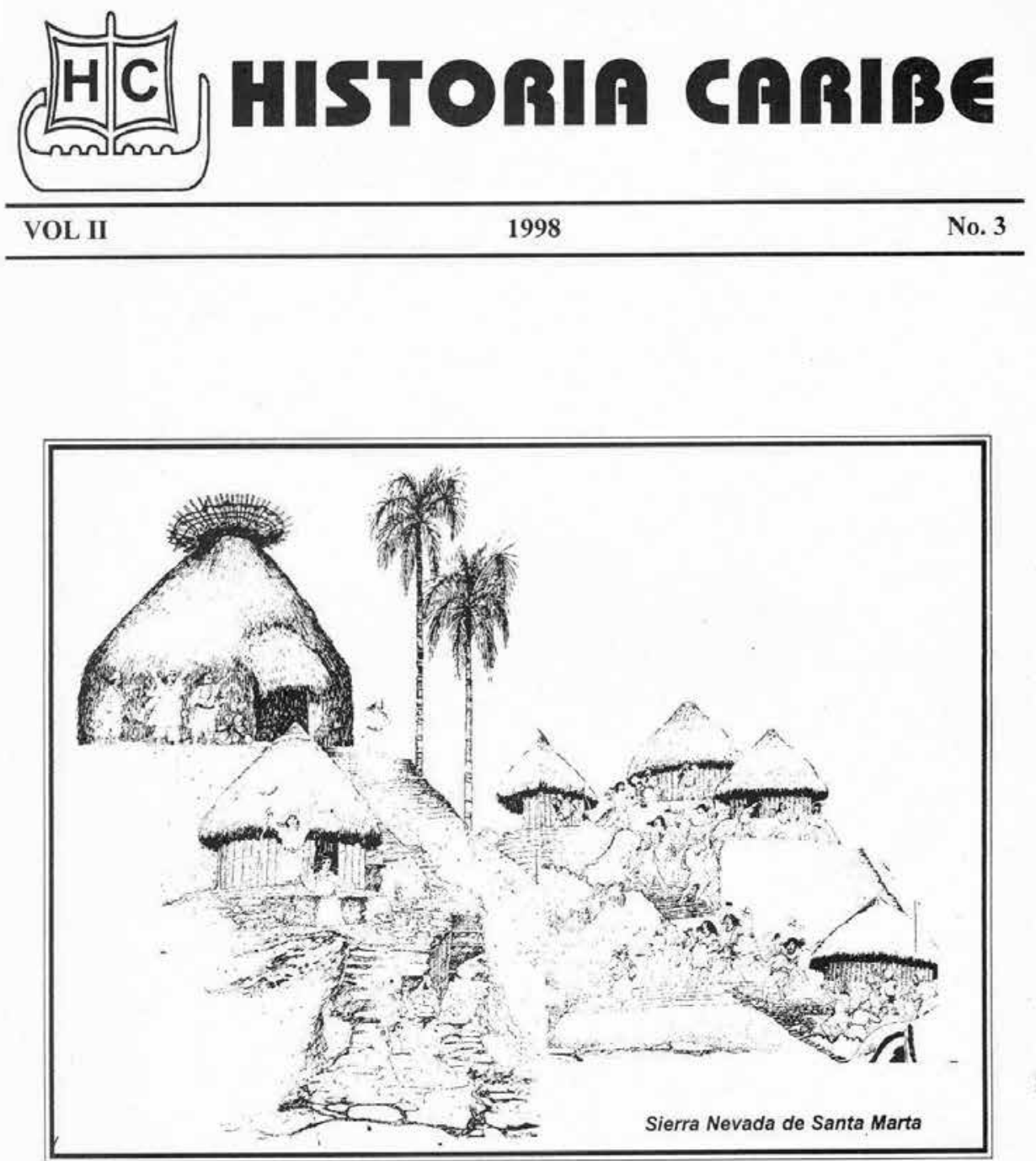

Barranquilla - Colombia

ISSN 0122-8803

Depósito Legal 3121 Ministerio de Cultura 


\title{
Riegos históricos y riegos contemporáneos en la Cataluña occidental llana. \\ El agua y el desarrollo económico y cultural (1750-1950)*
}

ENRIC ViCEDO-RIUS

\begin{abstract}
Profesor catedrático del Departamento de Historia de la Universitat de Lleida (España). Correo electrónico: vicedo@historia.udl.cat. El autor es Doctor en Historia; entre sus publicaciones recientes tenemos: "L’aprofitament històric de l'aigua a la Catalunya seca; una anàlisi a partir del patrimoni etnogràfic del terme de Torrebesses a la Vall Major (Segrià-Garrigues)", en Estudis d'Història Agrària No. 23 (2013) y "Propiedad de la tierra y desigualdad social en el mundo rural catalán de mediados del siglo XIX”, en Historia Agraria No. 23 (2014). Entre sus líneas de investigación tenemos las transformaciones de las sociedades agrarias y crecimiento económico, producción y mercado, el pequeño campesinado y mundo rural, solidaridades campesinas, y conflictividad y recursos, trabajos agrarios y transformaciones territoriales en Cataluña entre los siglos XVIII a XX.
\end{abstract}

Recibido: 25 de julio de 2014

Aprobado: 17 de septiembre de 2014

Modificado: 10 de noviembre de 2014

Artículo de investigación e innovación

DOI: http://dx.doi.org/10.15648/hc.26.2015.2

Este artículo forma parte de los proyectos: "Historia ambiental de los paisajes agrarios del Mediterráneo: orígenes, fuerzas económicas motoras, agentes sociales rectores e impactos ecológicos de la transformación del territorio" y "Cambios y continuidades en el hábitat y en la utilización del territorio en épocas de transición desde la edad media hasta nuestros días. Análisis del paisaje y sociedad", financiado por los Ministerios de Ciencia e Innovación (España), y de Economía y Competitividad (España). Los mapas 2 y 3 han sido elaborados por el Laboratorio de Cartografía de la Universitat de Lleida (España).

Esta publicación está bajo una licencia Creative Commons Reconocimiento-Compartir Igual 3.0

\section{(cc) BY-SA}


Riegos históricos y riegos contemporáneos en la Cataluña occidental llana. El agua y el desarrollo económico y cultural (1750-1950)

\title{
Resumen
}

Este trabajo analiza el impacto territorial y humano de los sistemas hidráulicos antiguos, especialmente las acequias de Pinyana y de Fontanet. Estos riegos han proporcionado una mayor regularidad en las cosechas, contribuyendo a perfilar el carácter de las comunidades. Compararemos estos procesos históricos con los desarrollados por "nuevos" regadíos contemporáneos: el Canal de Urgel a partir de la década de 1860. Superadas las dificultades sanitarias iniciales, el riego ha transformado los paisajes, ha contribuido al crecimiento económico y, ante problemas y conflictos, ha forjado una relación más compleja entre vecinos y entre los pueblos.

Palabras clave: Acequias y canales, impacto ecológico, desarrollo, comunidades de regantes, Cataluña occidental llana, siglos XVIII-XX.

Historical irrigation and contemporary irrigation in the plain Western Catalonia. Water and the economic and cultural development (1750-1950)

\begin{abstract}
This paper analyzes the territorial and human impact of the old hydraulic systems, especially the irrigation ditches of Pinyana and Fontanet. These irrigations have provided a greater regularity in the crops, contributing to shape the character of the communities. We will compare these historical processes with those developed by "new" contemporary irrigation: the Urgell Canal from the 1860s. Overcoming the initial health difficulties, irrigation has transformed the landscape, has contributed to economic growth, and facing with problems and conflicts, has forged a more complex relationship between neighbours and between villages.
\end{abstract}

Key words: Ditches and canals, ecological impact, development, communities of irrigators, plain Western Catalonia, 18th-20th centuries.

Irrigação histórica e irrigação contemporânea na planície ocidental de Catalunha. Água e o desenvolvimento económico e cultural (1750-1950)

Resumo

Este trabalho analisa o impacto territorial e humano dos sistemas hidráulicos antigos, especialmente as valas de irrigação de Pinyana e Fontanet. Estas irrigaçãos têm pro- 
porcionado uma colheitas mais regulares, ajudando a moldar o caráter de comunidades. Comparamos esses processos históricos com aqueles desenvolvidos pela irrigação contemporânea "nova": o Canal de Urgel, da década de 1860. Superar as dificuldades iniciais de saúde, irrigação transformou a paisagem, tem contribuído para o crescimento económico e confrontados com problemas e conflitos, forjou uma relação mais complexa entre vizinhos e entre as aldeias.

Palavras-chave: Valas e canais, impacto ecológico, desenvolvimento, comunidades de irrigação, Planície Ocidental Catalunha, XVIII-XX séculos.

\section{Irrigation historique et irrigation contemporaine igation dans la Catalogne occidentale plate. L'eau et le développement économique et culturel (1750- 1950)}

\section{Résumé}

Cet article analyse l'impact territorial et humain des vieux systèmes hydrauliques, en particulier les fossés d'irrigation de Pinyana et de Fontanet. Ces irrigations ont fourni une plus grande régularité dans les cultures, contribuant à façonner le caractère des communautés. Nous comparerons ces processus historiques avec ceux développés par «nouvelles» irrigations contemporaines: le Canal d'Urgell depuis les années 1860. Surmontées les initiales difficultés de santé, l'irrigation a transformé le paysage, a contribué à la croissance économique et, confrontés à des problèmes et des conflits, a forgé une relation plus complexe entre voisins et entre les villes.

Mots-clés: Fossés et canaux, impact écologique, le développement, les communautés d'irrigants, Catalogne occidentale plate, Ouest, XVIIIe-XXe siècles.

La Cataluña occidental llana dispone de un nivel de precipitaciones que equivale a la mitad de la evapotranspiración potencial. Los rendimientos sin riego son reducidos y dependen de las lluvias, con sequías frecuentes. Pero tiene recursos fluviales significativos, alimentados por la lluvia y el deshielo de las nieves del Pirineo. Este trabajo tiene por objeto analizar el impacto territorial y en la configuración de las comunidades campesinas de los sistemas hidráulicos de origen antiguo, centrándonos principalmente en las acequias de Pinyana y de Fontanet, en la comarca de Lleida. Estos riegos no solo han proporcionado un mayor crecimiento que el de 
las zonas de secano, sino que han contribuido a perfilar el carácter de las comunidades que gestionaban sus recursos. Ya en el siglo XX se desarrolla una alta conflictividad, en el momento en que el Estado obliga a crear una comunidad de regantes, que es vista con recelo por las comunidades del norte de la comarca de Lleida (el Segrià).

Efectuado este análisis, compararemos estos procesos históricos con los desarrollados por "nuevos" regadíos contemporáneos: el Canal de Urgell a partir de la década de 1860. Superadas las dificultades sanitarias iniciales, el riego ha transformado los paisajes, ha contribuido al crecimiento económico y, ante problemas y conflictos, ha forjado una relación más compleja entre vecinos y entre los pueblos.

El desarrollo económico mediante la agricultura de regadío no ha sido un camino fácil, y han debido superarse problemas graves como el paludismo en ambos sistemas o bien, en el caso de las acequias de Lleida, la situación de abandono de una parte importante de la zona de riego como consecuencia de la prohibición de construir viviendas fuera de los muros de la ciudad durante un siglo y medio.

\section{INTRODUCCIÓN}

Cataluña es una región ubicada en la parte nororiental de la Península Ibérica. La Cataluña occidental llana ${ }^{1}$ se caracteriza por un régimen climático que dificulta de manera significativa la actividad agraria. Las precipitaciones medias anuales son inferiores a $400 \mathrm{~mm}$ anuales. Para el periodo 19391970, en la estación meteorológica de Lleida se recogieron 385 mm (P), siendo la evapotranspiración potencial (ETP) más del doble, en concreto $844 \mathrm{~mm}$. El resultado es fácil de evaluar: un índice de humedad de 0,46 [385/844] y un déficit hídrico [P-ETP] medio anual de $459 \mathrm{~mm}$. El gráfico 1 muestra, por meses, las precipitaciones y las ETP totales así como las

1 Incluye las comarcas del Segrià, el Urgell, el Pla d'Urgell, las Garrigues y la zona llana de la Noguera. A la comarca del Segrià pertenecen las siguientes poblaciones que se citan: Lleida, Albatàrrec, Alcarràs, Alguaire, Almacelles, Almenar, Alpicat, Corbins, Montoliu, Sudanell, Torrebesses, Torrefarrera y Torres de Segre; a la comarca de la Noguera pertenece Térmens; al Pla d'Urgell, Ivars d’Urgell y Vila-sana. 
temperaturas medias. Se observa que las ETP son, muy a menudo, superiores a las precipitaciones. Este déficit hídrico resulta evidente en el gráfico 2 desde mayo hasta septiembre, con un máximo en julio. Por otra parte, la oscilación térmica se sitúa en torno a los 20 grados. Ello puede significar heladas invernales de olivos haciendo inviable la cosecha o bien la pérdida de frutos en la primavera por fríos cuando las plantas ya han florecido.

\section{Gráfico 1}

Climograma de Lleida

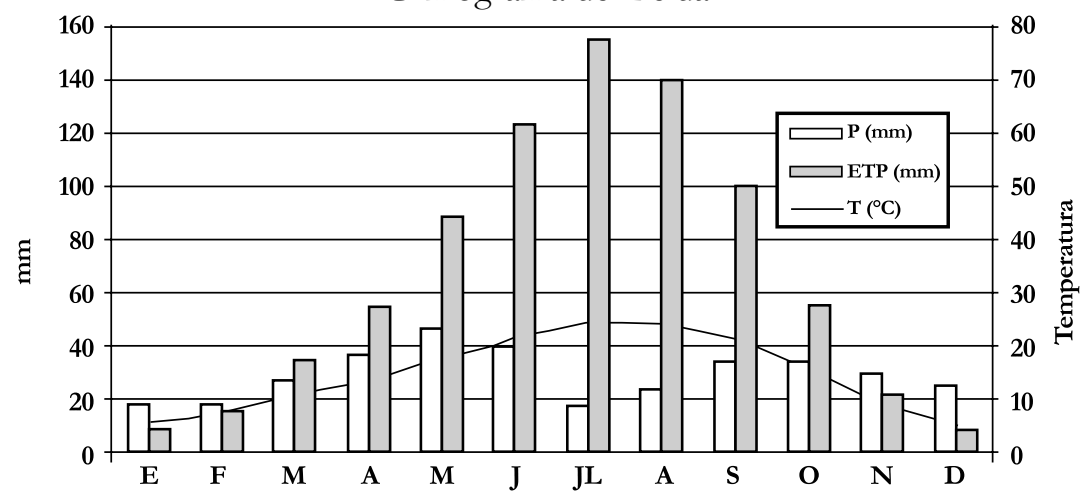

Fuente: Enric Vicedo, Jaume Boixadera y José Ramón Olarieta, "Sistema hidráulico, organización de los riegos y usos del agua en la huerta de Lleida (1830-1950)", en El agua en los sistemas agrarios, Ramón Garrabou y José Manuel Naredo (coords.).

(Madrid: Argentaria/Visor distribuciones, 1999), 225-254.

\section{Gráfico 2}

Déficit hídrico medio mensual, Lleida, 1939-1970

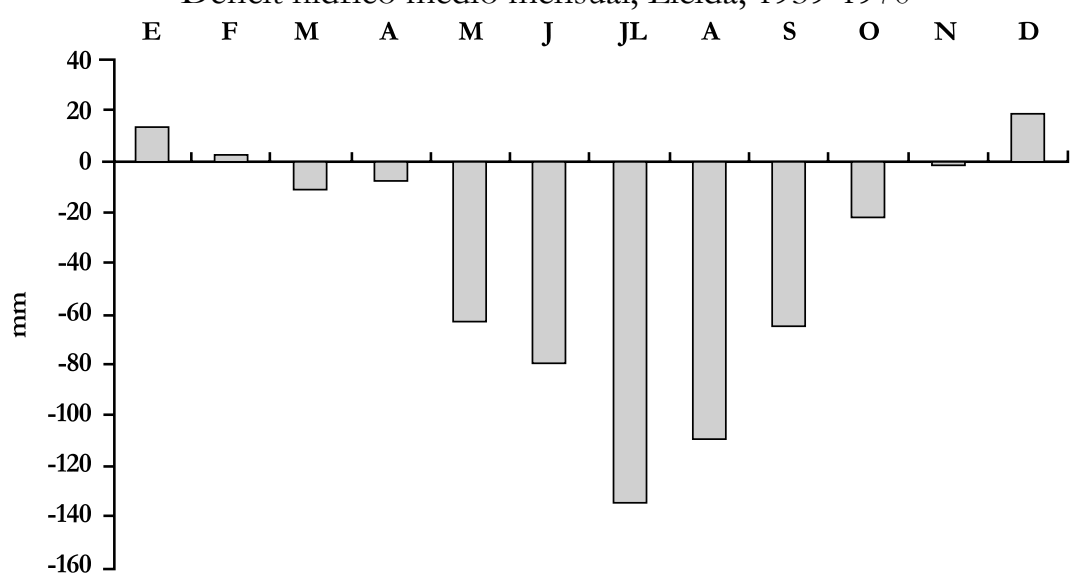

Fuente: Elaboración propia a partir de Francisco Elías y Luis Ruiz, Agroclimatología de España, Estación 580, (Madrid: Ministerio de Agricultura-Instituto Nacional de Investigaciones Agrarias, 1977). 
Disponemos de documentos diversos en los cuales se hace referencia a este impacto de las condiciones climáticas. Por ejemplo, en 1723 el Diputado del corregimiento de Lleida argumentaba ante las autoridades borbónicas de Barcelona en relación a las calidades y rendimientos que se habían establecido en el primer catastro de $1716^{2}$.

"Como siendo tan contingentes en el Llano de Urgel y en los demás secanos del corregimiento las cosechas, que lográndose dos en el transcurso de diez años se tiene por buen tiempo, se les considera por jornal en los más el producto de 8, 6 y 4 cuarteras [73,36 litros] de trigo anuales respectivas a primera, segunda $y$ tercera calidad de las tierras, y a algunos más; siendo así que habida proporción a lo incierto, y por lo regular de las cosechas, no llega de muchos años con otros a la mitad su producto”.

El Comendador Hospitalario de Térmens, en la comarca de la Noguera, explicaba 60 años después,

"sent com és casi tot lo terme de Termes de secà, queda subgecte a las vicisituts del temps, esterelitat de ayguas, y falta de pluja, que regularment se experimentan en la comarca de Urgell ${ }^{4}$, y per est motiu succeheix freqüentment deixarse de sembra ditas terras, o passa un, dos, y tres anys sens que persevesca dit senyor comanador útil algun de ellas per rahó del delme i quinsè...”5.

El problema era tan grave que cuando en 1773 Melcior Guàrdia obtuvo del rey la señoría sobre el término despoblado de Almacelles, en la comarca del Segrià, encargó al arquitecto barcelonés Mas Dordal el diseño

2 "Escrito de un representante del Corregimiento de Lleida" (1723), Archivo Municipal de Lleida (AML), Correspondencia, registro 881, folio 758.

3 "Lo senyor don Joseph de Copons, comanador de Térmens (...) consultà als infraescrits sobre varios punts acerca lo ús de sas respectivas facultats, y major adelantament de sa encomanda....", Archivo de la Corona d'Aragó (ACA), Sant Joan de Jerusalem (SJJ), Armario 6, 1egajo 2.

4 Aquí se utiliza el término comarca de Urgell en referencia a toda la zona llana que estudiamos.

5 "Siendo como es casi todo el término de Térmens de secano, queda sujeto a las vicisitudes del tiempo, esterilidad de aguas, y falta de lluvia, que regularmente se experimenta en la comarca de Urgell, y por este motivo sucede frecuentemente que se deja de sembrar dichas tierras, o pasa uno, dos, y tres años sin que reciba dicho señor comendador algún útil de ellas en concepto del diezmo y el quinceno...". 
de un nuevo pueblo para repoblar ${ }^{6}$ y, en 1780 , le encargó el diseño de una acequia que tomaría las aguas en un punto posterior a la toma de la acequia de Pinyana. En el mapa 1 se puede observar en trazo grueso descendente el curso que debería tener la nueva acequia. En el proyecto detallado ${ }^{7}$, que se realiza tras un minucioso trabajo de campo indica:

"De todo lo cerca referido se evidencia que las tierras que de nuevo se intenta beneficiar con las aguas del río, no es ni debe entenderse como para regar Huerta, si únicamente para con aquellas aguas suplir la falta de una, dos, o tres lluvias si estas no vienen en los respectivos tiempos desde la siembra hasta la siega. Ni tampoco con esto se intenta persuadir el que se deje de sembrar frutos de verano como Cáñamo, Mijo, Legumbres, y otros semejantes, pues esto puede seguirse según, y conforme el agua llevará el río, bien que para ello es muy propio el observarse regularmente abundantes en los meses de Mayo, Junio y Julio por ser el tiempo en que se derriten las nieves de los Montes, y en ellos comúnmente es siempre crecido el dicho río".

Como puede comprobarse, y todo ello se argumenta con mucho detalle en el proyecto, se trata, fundamentalmente, de dar algún riego que supla la falta de lluvias que es muy recurrente en Almacelles y en toda la región de Lleida. Es un proyecto paliativo que no ha de significar, al menos en primera instancia, el desarrollo de una huerta orientada a un mercado exterior. Los déficits hídricos son tan significativos que, en una visita a Almacelles de un representante del señor en $1784^{\circ}$, los pobladores reclamaban un conjunto de acciones relativas a disponer de agua: dos pozos, uno para regar una partida rural y el otro debería tener una conducción metálica hasta el pueblo para evitar el transporte manual y regar los huertos, una acequia que recogiera las aguas de la parte alta del término para regar el llano, y finalmente construir un pequeño pantano que recogiera las aguas

6 Enric Vicedo-Rius, "La colonització rural a la catalunya occidental. Almacelles, 1750-1830", en Jornades Internacionals d'Urbanisme i Arquitectura de la Illustració (Lleida: Ajuntament d'Almacelles-Pagès Editors, Almacelles, 2009), 17-30.

7 "Escrit que conté la Notícia del Riu Noguera y Projecte del Us de sas ayguas per a Regar las Terras de Almasellas" Documentación del Barón d'Esponella (DBE), Copia conservada en el Ayuntamiento de Almacelles [31.1].

8 "Nota de lo que me han demanat los Pobladors per copsar la entera felicitat". DBE. 


\section{Mapa 1}

Plano del proyecto de acequia para regar Almacelles según proyecto de Mas Dordal, 1780

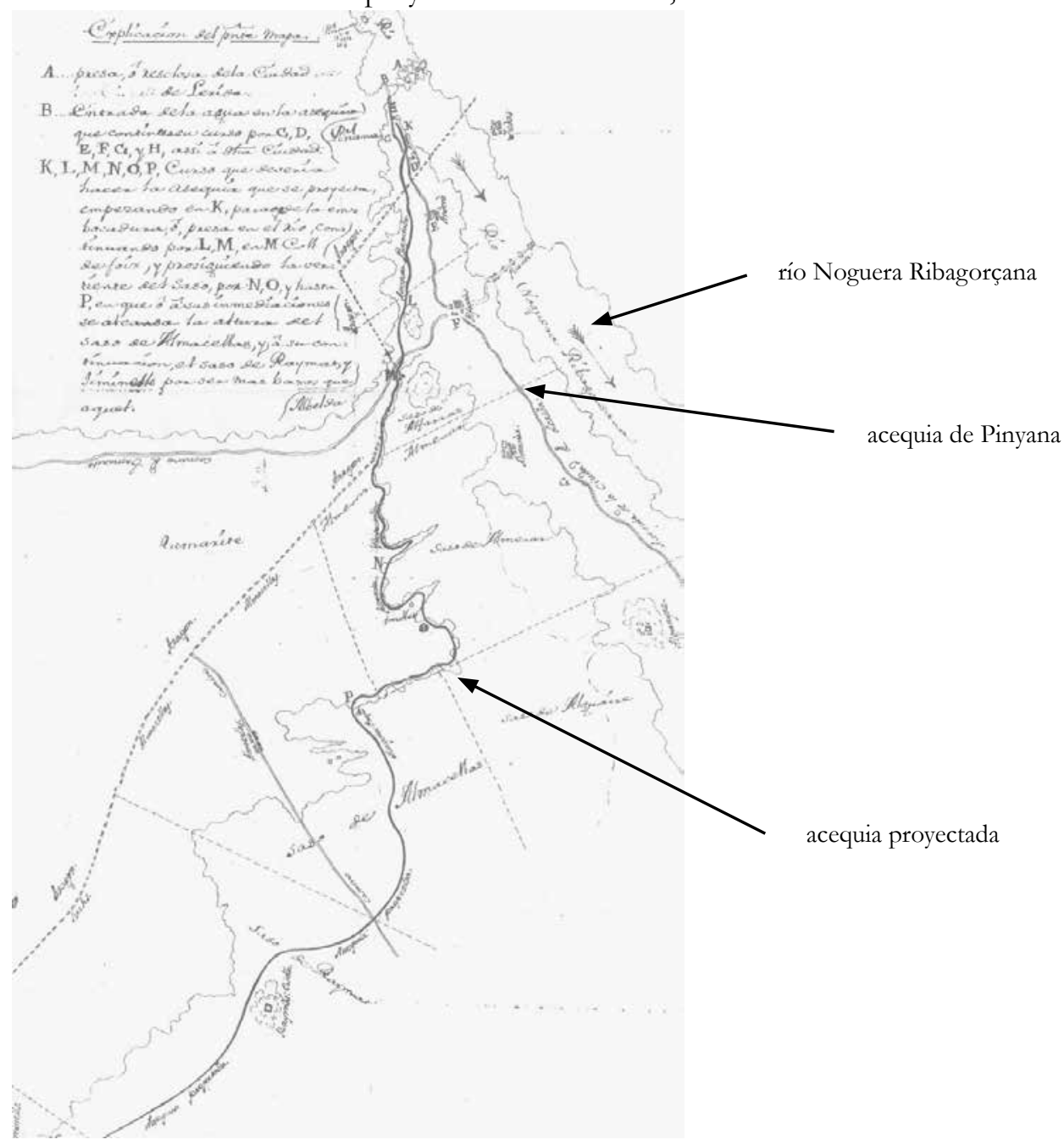

Fuente: Documentación del Barón de Esponellà. Ayuntamiento de Almacelles.

de la zona alta de la Saida y, mediante "aigüeres" llevarla a la parte baja. Se pedía también otra cisterna en el pueblo e intentar, aprovechando el agua

9 Pequeños surcos realizados en el suelo para canalizar pequeñas cantidades de agua de lluvia. Este sistema ha sido observado en otras áreas de la Cataluña llana, como en la comarca de las Garrigues. Ignasi Aldomà y Enric Vicedo, "L'aprofitament històric de l'aigua a la Catalunya seca; una anàlisi a partir del patrimoni etnogràfic del terme de Torrebesses a la Vall Major (Segrià-Garrigues)", Estudis d'Història Agrària, Vol. 23 (2012): 13-36. 
procedente del pantano, instalar un molino para no tener que realizar la molienda en los pueblos vecinos de Alguaire o Almenar.

Paralelamente, el Intendente de Zaragoza (Aragón), el 23 de agosto de 1782, comisionó al ingeniero Manuel Inchauste para que informara sobre la construcción del proyectado Canal de Tamarit. Este será el origen del Canal de Aragón y Cataluña. La fuerza de esta propuesta tuvo como resultado que Mas Dordal realizara informes muy detallados del proyecto de Inchauste, asumiendo Guàrdia la propuesta procedente de la vecina región de Aragón. Almacelles será el primer término catalán que será regado en 1910 por el nuevo canal de Aragón y Cataluña, 130 años después del proyecto de Mas Dordal ${ }^{10}$.

El mapa 2 muestra, de manera sintética, el aprovechamiento actual de los recursos hídricos que, a través de los ríos, y mediante el almacenamiento en embalses, permite que una zona -la Cataluña occidental llana- haya superado los problemas que acabamos de referenciar para lugares como Térmens, Almacelles, o bien el Urgell. El Canal de Urgell no será una realidad hasta la década de 1860, el de Aragón y Cataluña no empezará a regar en este último territorio hasta 1910. Nos centraremos ahora en las acequias históricas que han regado desde tiempos anteriores la zona de Lleida: el canal de Pinyana, la acequia de Fontanet y la acequia de Torres de Segre ${ }^{11}$. Analizaremos su naturaleza, su forma de gestión y en qué sentido ha ayudado a configurar la personalidad de un territorio y sus comunidades humanas ${ }^{12}$.

10 A.A.V.V., Historia de una tierra. Centenario del Canal de Aragón y Cataluña, 1906-2006, (Binéfar: Ediciones 94-Comunidad, 2006), especialmente los tres textos del capítulo 1 dedicados a la historia del canal.

11 En la actualidad las hectáreas regadas en el término municipal de Lleida son las siguientes: Canal de Pinyana (6.892 ha), Acequia de Fontanet (973 ha), Canal de Urgell (5.595 ha), Canal de Aragón y Cataluña (6.768 ha), y en construcción el Canal de les Garrigues Baixes (949 ha).

12 Un panorama general de los riegos contemporáneos en Cataluña se ofrece en Ramon Garrabou Segura y Josep-María Ramon-Muñoz, "Aigua, agricultura i regadiu a la Catalunya contemporània, 1800-2010”, Estudis d’Història Agrària, Vol. 23 (2012): 27-57. 


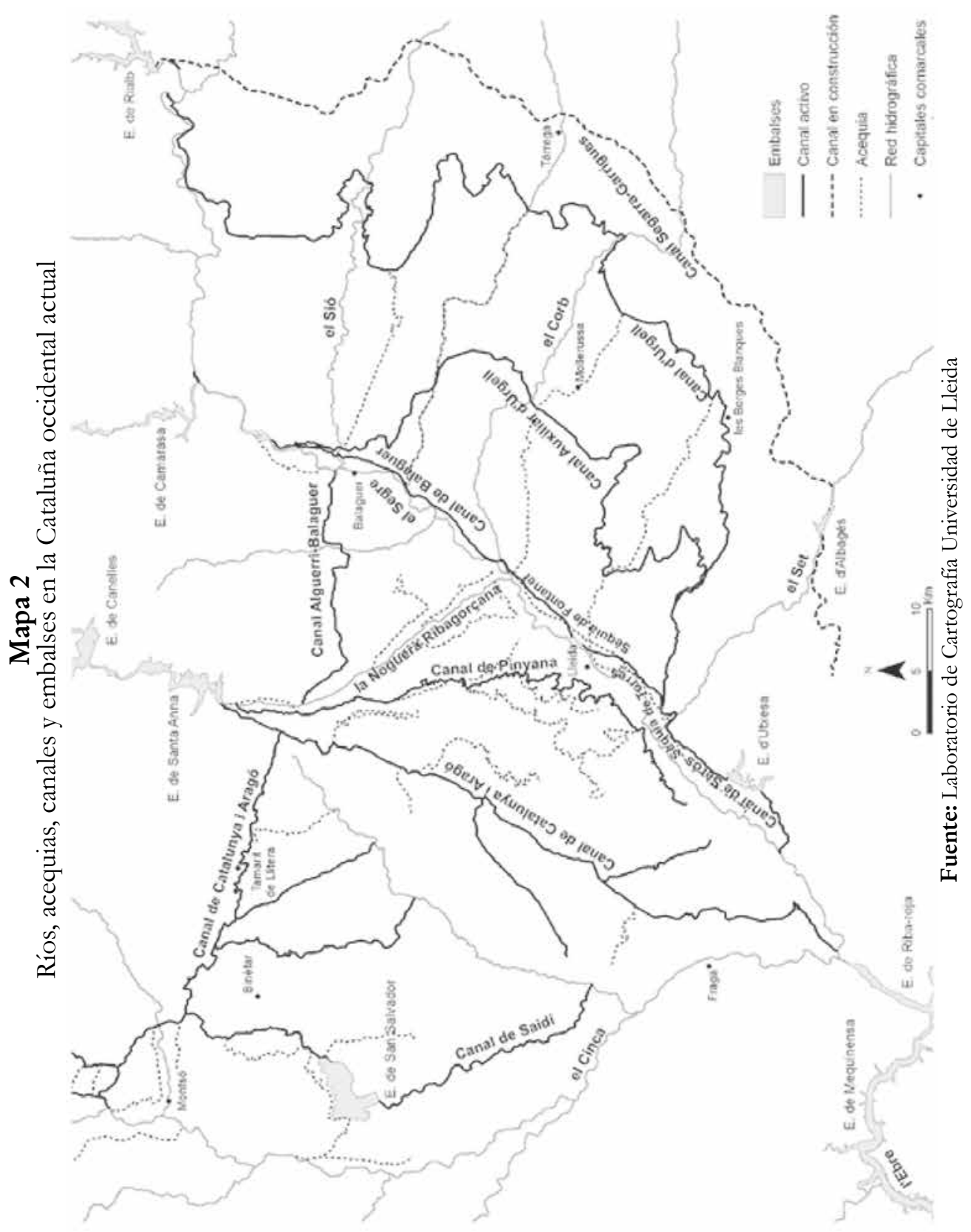




\section{La configuración histórica de los Riegos de PinYana y Fon- TANET $^{13}$}

“... donem a vosaltres, tots els pobladors i habitants o residents en la ciutat de Lleida, tant els presents com els futurs, cases i patis i hortes i finques i tota la ciutat de Lleida (...). Us donem també tot el territori de la ciutat de Lleida, ja cultivat, ja d'erm, així com tots els seus termes i pertinences i totes les seves entrades i sortides perquè tingueu allí les vostres cases i les vostres heretats (...). Us donem també els prats i les pastures, fonts i aigües, boscos $\mathrm{i}$ llenya i la caça, la plana i els turons per a tots els vostres usos, $\mathrm{i}$ pastura i aconduir tots els vostres ramats" ${ }^{14}$.

A pesar de la claridad con que Ramon Berenguer IV, conde de Barcelona, y Ermengol VI, conde de Urgell, ceden las aguas a los repobladores de Lleida en 1150, posteriormente Alfons I el Cast concede los riegos del Segrià (Pinyana) y Fontanet a Ramon Sassala y a Guillem de Basella. A cambio de cobrar cequiajes ${ }^{15}$ se les obligaba a expandir el área de riegos. En diversas operaciones, entre 1190 y 1213, el ayuntamiento de Lleida compró los derechos de riego. Desde 1229, fecha en que finalizó el pago de la última operación financiera, hasta 1758, el ayuntamiento de Lleida gozó del control de los riegos del Segrià (Pinyana) y Fontanet. En 1242 el rey confirma el derecho del ayuntamiento a percibir el cequiaje y en 1264, coincidiendo con el cambio del estatuto municipal que pasa de Consolat (Consulado) a Paeria ${ }^{16}$, se crean las Prohomenies del Segrià y de Fonta-

13 Romà Sol, R. y Carme Torres, Historia de un Canal, 1147-1974. (Lleida: Autoedición, 1974); Enric Vicedo-Rius, (dir.), Els canals de Pinyana i Fontanet. L'aigua com a factor transformador de la regió de Lleida, (Lleida: Pagès editors, 2006).

14 "Carta de Población de Lleida", 1150, reproducida en Rafael Gras i Esteva, La Paheria de Lleida. (Lleida: Ayuntamiento, 1911), 170 y ss. “... damos a vosotros, todos los pobladores y habitantes o residentes en la ciudad de Lleida, tanto los presentes como los futuros, casas y patios y huertas y fincas y toda la ciudad de Lleida (...). Os damos también todo el territorio de la ciudad de Lleida, ya cultivado, ya yermo, así como todos sus términos y pertinencias y todas sus entradas y salidas para que tengáis allí vuestras casas y heredades (...). Os damos también los prados y pastos, fuentes y aguas, bosques y leña y la caza, el llano y los montículos para vuestros usos, y el pasto y conducir todos vuestros rebaños".

15 El cequiaje [“sequiatge” en catalán] era la aportación económica que debían satisfacer los regantes por el uso de los riegos. Se establecía en una cantidad por unidad de superficie regada.

16 Mediante el nuevo estatus municipal se organiza la ciudad, el término de Lleida y sus riegos. 
net $^{17}$. Almenar quedará al margen del pago del cequiaje ya que en 1151 Ramón Berenguer IV concedió la acequia de Almenar a cien hombres que repoblaron la región. A partir de este momento y hasta mediados del siglo $\mathrm{XX}$ los habitantes gestionaron autónomamente los riegos con la acequia de Pinyana.

Ante los conflictos entre regantes y ayuntamiento de Lleida, el Real Auto de 20 de julio de 1758 crea la primera Junta de Cequiaje ${ }^{18}$ con carácter provisional, hasta la aprobación definitiva en 1794 de las Ordenanzas de la Junta de Cequiaje. La junta definitiva estará formada por seis miembros: un regidor, un prebendado del cabildo de la catedral, un eclesiástico del clero menor, dos labradores y un hacendado de la clase de los gaudines ${ }^{19}$, y será presidida por el gobernador o su alcalde mayor. El gaudín se añade a los cinco anteriores ya presentes en la junta de 1758. Uno de los hechos fundamentales que recogen las ordenanzas y que era ya consuetudinario desde los tiempos medievales era la preeminencia del riego sobre la molturación. Este hecho resulta evidente en el caso del término de Lleida.

"La Junta siempre que experimente necesidad del riego en cualquiera de dichas dos huertas con peligro conocido de perderse los frutos si no se les facilita, podrá quitar el agua de los molinos de harina, y los molineros en estos casos deberán suspender su curso bajo la pena de diez libras, pero la Junta deberá proceder en este asunto con prudente economía no privando de una vez el agua a todos los molinos para que no falte el abasto de harina, sino progresivamente socorriendo los campos por su orden. Y si los molineros no obedeciesen se les tomarán las anadillas, y además serán executados por la predicha pena"20.

17 Una "prohomenia" era la institución creada para la administración de un tema municipal, en este caso la gestión de las dos acequias.

18 "Ordinaciones de la Junta de Distribución de riegos y administración del Sequiatge de la Ciudad de Lérida establecida de Orden del Real y Supremo Consejo de Castilla en el año 1758”, AML, Caja 1416.

19 En general propietarios de profesión liberal.

20 "Molinos y balsas de cáñamo", Real Despacho de Ordenanzas dispuestas para el gobierno y administración de las Azequias de la Ciudad de Lérida...., (Lleida: Buenaventura Corominas, 1802), 55-57. 
Semejantes limitaciones se recogían en los contratos de arriendo de los dos molinos municipales, el de Vilanoveta y el de Cervià. Se advertía que mientras circulase agua para mover una muela en uno de los dos molinos, se debería pagar el precio total del arriendo. Solo en caso de ausencia total de agua en los dos molinos, el ayuntamiento compensaría las pérdidas de los molineros ${ }^{21}$.

Sin lugar a dudas, esta preeminencia del riego sobre la molturación arranca del modelo hidráulico andalusí2 ${ }^{2}$, en contraposición con el modelo hidráulico feudal que prioriza la molturación ya que la mayor parte de los molinos son monopolios señoriales. Los señores -y en su caso los arrendatarios de derechos señoriales- obtienen importantes rentas cuando la escasez de cereal en el mercado posibilita obtener precios elevados del mismo pero de tipo panificable y la harina, especialmente durante los meses finales del año agrícola cerealista (abril, mayo, junio).

\section{Gráfico 3}

Coeficientes de caudal del río Segre (1912-29) caudal (media anual $=1): 12,23 \mathrm{~m} 3 / \mathrm{s}$ en la Seu d'Urgell (Pirineo) y $90,38 \mathrm{~m} 3 / \mathrm{s}$ en Lleida

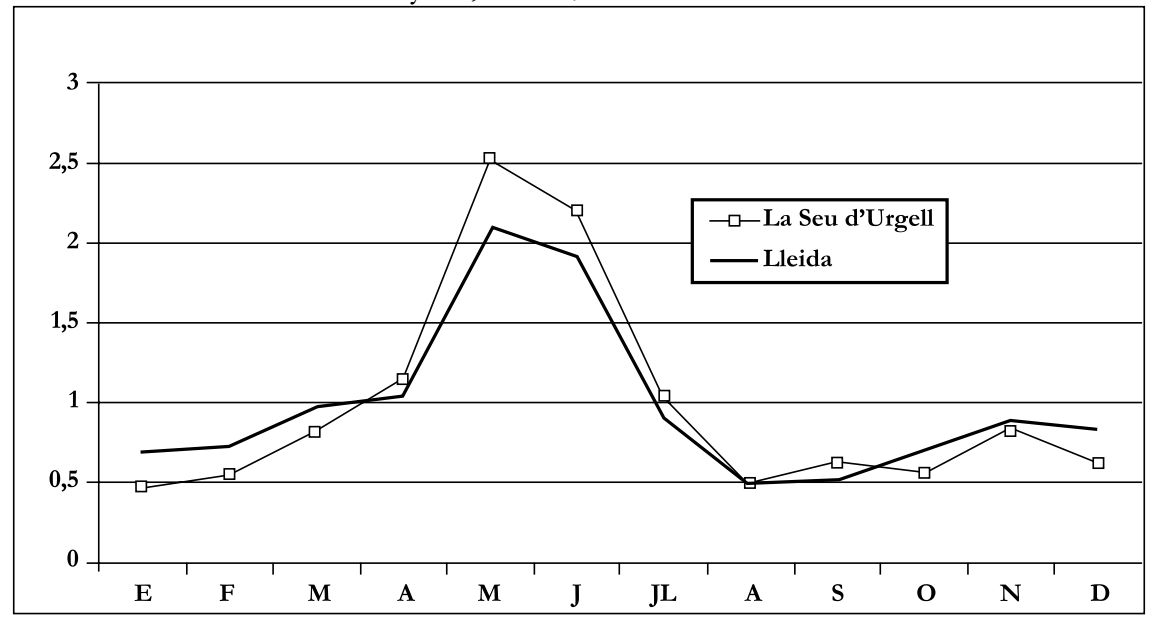

Fuente: Lluís Solé Sabarís, L. (dir.), Geografía de Catalunya, vol. 1. (Barcelona: AEDOS, 1958).

21 AML, Libros de arrendamientos de propios de la ciudad de Lleida.

22 Sin embargo, la organización territorial andalusí experimentó cambios fundamentales por parte de los feudales. Véase lo sucedido en la huerta de Rufea, dentro del término de Lleida. Xavier Eritja, "Dominicum comitis: estructuració feudal de l'horta urbana de Rufea (Lleida) durant la segona meitat del segle XII", en Terra, aigua, societat i conflictivitat a la Catalunya Occidental. Vicedo-Rius, Enric (ed.), (Lleida: Pagès editors, 2000), 25-46. 
Las ordenanzas de la Junta de Cequiaje de 1794 prevén, además del reparto del agua por días y términos, acciones especiales para los meses de verano, sobre todo cuando el río lleva caudales muy menores, aunque en julio equivalen a la media anual y en el resto de verano y otoño no bajan nunca de la mitad del caudal medio anual. El uso estratégico de estos recursos hídricos puede contribuir a salvar "tardanies"23.

"Y por cuanto en muchas ocasiones de Verano y Estío se experimenta que aún esto no es suficiente para la participación general de los riegos, establecemos: Que la Junta en uso de su dirección económica, pueda nombrar un Repartidor de aguas para dichas ocasiones, o más si los halla convenientes, y en el Estío pueda también prohibir el riego de los rastrojos, o dar cualesquiera otras providencias para remedio de los frutos pendientes" 24 .

\section{La gestión de las acequias de Pinyana y de Fontanet}

El "sequiatge" (cequiaje) que pagaban anualmente los regantes del término de Lleida, y que afectaba durante el siglo XVIII a un máximo 10.000 jornales de tierra (4.367 ha) consistía en uno o dos cuartanes de trigo por jornal regado ${ }^{25}$. Una tierra de calidad mediana podía rendir ocho cuarteras $^{26}$ de trigo que, a razón de doce cuartanes por cuartera, totalizan 96 cuartanes. Es fácil concluir que el cequiaje significaba entre un 1 y un $2 \%$ en las tierras de calidad media, algo mayor en las de menor rendimiento y menor en las de primera calidad que producían 10 cuarteras por jornal.

Puede entenderse que los payeses de Lleida consideraban los riegos de Pinyana y Fontanet como algo propio, de uso casi gratuito, ya que solo

23 Productos que se recolectan después del verano.

24 "Riegos y conductos menores", Real Despacho de Ordenanzas..., 46-55.

25 El cuartán de trigo por jornal era la cuota más frecuente. Era la doceava parte de una cuartera de 73,36 litros; por tanto el cuartán era poco más de seis litros. Por ejemplo, entre 1719 y 1742 se mantuvo en esta cifra, aumentándose a un cuartán y medio en los años 1743-1748 por el déficit generado por un menor ingreso al cultivarse menos tierras. En coyunturas especiales, como los años 16721674, se fijaron dos cuartanes por jornal. "Memòria del número de jornals y cantitat de blat que se trobe en los llibres de sequiatge des de 1719 inclusive fins a 1733..." y "Memòria dels jornals de terra que se troben continuats en los llibres de sequiatge des de 1734 inclusive fins a 1748...", AML, sección siglo XVIII, caja 22; "Informe sobre el cequiaje", AML, correspondencia, 1726-1727, registro 884 , folio 183 y ss.

26 La cuartera es una medida de capacidad que en Lleida equivale a 73,36 litros. 
se pagaba una cantidad limitada para cubrir los gastos corrientes de mantenimiento de las acequias. El hecho de formar parte de una comunidad de regantes les proporcionaba toda una serie de derechos en el uso de las aguas y les exigía una serie de responsabilidades dirigidas al mantenimiento de las infraestructuras y a no dificultar el riego de las fincas que estaban a continuación. Todo ello estaba especificado en las ordenanzas.

\section{Cuadro 1}

Censos pagados anualmente a la Junta de Cequiaje por los regantes del Segrià

\begin{tabular}{|c|c|c|c|}
\hline $\begin{array}{c}\text { Contribuyente } \\
\text { a la Junta - siglo XVIII }\end{array}$ & libras* & $\begin{array}{l}\text { Contribuyente } \\
\text { a la Junta - } 1851\end{array}$ & libras \\
\hline Regidores de Alcoletge & 15,0 & Alcalde de Alcoletge & 15,0 \\
\hline Regidores de Soses & 5,0 & Alcalde de Soses & 5,0 \\
\hline Regidores de la Portella & 11,0 & Alcalde de la Portella & 11,0 \\
\hline Regidores de Vilanova de Segrià & 30,0 & Alcalde de Vilanova del Segrià & 30,0 \\
\hline Regidores de Benavent y Alandí & 23,4 & Regidores de Benavent y Alandí & 23,4 \\
\hline Regidores de Alguaire & 25,0 & Alcalde de Alguaire & 25,0 \\
\hline Regidores de Alcarràs & 43,8 & Alcalde de Alcarràs & 43,8 \\
\hline Cabildo de Lleida por Montagut & 20,0 & Cabildo & 20,0 \\
\hline $\begin{array}{l}\text { Gran Priorato de Catalunya o regi- } \\
\text { dores de Corbins }\end{array}$ & 37,4 & Gran Priorato & 37,4 \\
\hline Abadesa de Alguaire & 19,0 & & \\
\hline Comendador de Torres de Segre & 30,6 & $\begin{array}{l}\text { Franscesc Miret por la Encomienda } \\
\text { de Torres de Segre }\end{array}$ & 30,9 \\
\hline $\begin{array}{l}\text { Marqués de Benavent por tierras del } \\
\text { Cap }\end{array}$ & 4,0 & Marqués de Benavent & 4,0 \\
\hline \multirow[t]{8}{*}{ Obispo de Lleida por Sant Ruf } & 2,0 & Obispo de Lleida & 2,0 \\
\hline & & Marqués de Alfarràs & 5,1 \\
\hline & & Miquel Gort & 12,5 \\
\hline & & Manuel Fuster Arnaldo & 12,5 \\
\hline & & José Bañeres de Alguaire & 25,0 \\
\hline & & José Antonio Morlius & 15,0 \\
\hline & & Mariano Quer & 19,0 \\
\hline & & Pedro Capita & 1,1 \\
\hline TOTAL & 266,2 & TOTAL & 474,5 \\
\hline
\end{tabular}

Fuente: "Llibres de la collecta del sequiatge", siglo XVIII; y "Razón de los censos cobrados en el año de 1851". Archivo de la Junta de Sequiatge de Lleida.

* Tres libras barcelonesas equivalían a ocho pesetas. 
Lo mismo cabe decir de las comunidades anteriores o posteriores a la de Lleida. Las mismas ordenanzas establecen los turnos para el riego, asignando días a cada población, y estableciendo normas que la Junta puede ejecutar, pero respetando la organización interna de cada comunidad de regantes.

El cuadro 1 refleja los censos pagados a la Junta durante el siglo XVIII como resultado de acuerdos producidos en siglos anteriores, y la distribución de los pagos en 1851 en pleno proceso de reforma agraria liberal. Se trata de censos enfitéuticos fijos, que irán perdiendo valor real durante la segunda mitad del siglo XVIII cuando los precios aumentan en el contexto de un movimiento general en Europa ${ }^{27}$. Los contratos enfitéuticos permitían la cesión del dominio útil de un bien o servicio a una persona o institución, reteniéndose su titular el dominio directo, lo cual le permitía percibir un censo anual que podía establecerse en dinero o en especie, pudiendo exigirse esta última como cantidad fija o bien parte de frutos. La enfiteusis es más que un simple contrato, ya que en torno a ella se articulan gran parte de las relaciones sociales en el campo catalán ${ }^{28}$. Como indicó Vilar, en los documentos fiscales no se distingue entre plena propiedad o casi propiedad enfitéutica ${ }^{29}$.

En definitiva, diversos ayuntamientos disponen del dominio útil a perpetuidad de las aguas de riego, principalmente de las acequias de Pinyana o de Fontanet a cambio de pagar un censo anual. Como sucedía en el término de Lleida, cada comunidad se organiza para recaudar el dinero para pagar el censo y hacer frente a los gastos generales de mantenimiento de las zanjas principales. La gestión de los riegos contribuye a reforzar el sentimiento de pertenencia a una comunidad humana, cuya prosperidad se fundamenta en gran parte en poder garantizar un mínimo de rendimientos gracias a la posibilidad de regar. La agricultura de regadío, y especialmente la producción de hortalizas, exige también una mayor aportación de tra-

27 Enric Vicedo-Rius, "Mercado y precios. El almudí de Lérida, 1700-1833”, Historia Agraria, Vol. 45 (2008): 53-88.

3428 Eva Serra, "Notes sobre els orígens i l'evolució de l'emfiteusi a Catalunya", Estudis d'Historia Agrària, Vol. 7 (1983): 127-138.

29 Pierre Vilar, "La quasi-propietat: l'establiment emfitèutic", en Pierre Vilar, Catalunya dins l'Espanya moderna, v. 3, (Barcelona: Edicions 62, 1966), 554-561. 
bajo por unidad de superficie, lo cual favorece la ocupación campesina. Además cualquier abuso en el uso del agua o carencia en la limpieza de las acequias es debatido y resuelto en el marco de la comunidad de regantes.

En el cuadro 1 se observa que algunos señores tienen agua acensada. Uno de los casos más significativos es el del Comendador de Torres de Segre, quien dispone de una acequia propia que tiene su origen en Lleida y llega a Torres de Segre - en la parte sur de la comarca de Lleida (el Segrià)-, fertilizando también las huertas de Albatàrrec, Sudanell y Montoliu. El comendador hospitalario de Torres de Segre era el propietario de la acequia y, por tanto, debía hacerse cargo de los gastos de reparación y limpieza. El común debía pagar a un acequiero quien juraría el cargo ante el comendador o sus representantes. Dos ejemplos nos muestran cómo la gestión de los riegos era un motivo de coordinación campesina y de negociación con el comendador. En 1711, en la posguerra de Sucesión -que en la zona finaliza con la toma de Lleida en 1707-, el común propone responsabilizarse de los trabajos de reparación y limpieza necesarios para que vuelva a fluir el agua por la acequia. La propuesta va más lejos: el ayuntamiento propone asumir toda la gestión de la acequia y el pago del censo al ayuntamiento de Lleida a cambio de que se suprima la "sisena", o sea la sexta parte de los frutos de la huerta que pagan al señor. Además ofrecen algunos bienes municipales más para compensar. No parece que el acuerdo se concretara. Los regantes no pagan cequiaje pero una sexta parte de la producción como renta por la señoría territorial es importante si se considera que existen otras muchas detracciones señoriales por señorío territorial y banal ${ }^{30}$.

Cien años más tarde, en 1804, y ante las necesidades de agua no satisfechas en la huerta de Torres de Segre, a propuesta del común se llega a una concordia con el comendador para hacer una presa nueva y una acequia derivada que aporte más agua a la del comendador, beneficiando todos los pueblos que riegan. El comendador condona la "sisena" durante dos años, cede durante el mismo tiempo la balsa de empozar y macerar el cáñamo y el prado para extenderlo, y el trujal, la bodega, cubas y otros enseres.

30 Enric Vicedo-Rius, "La conflictividad en las Terres de Lleida en el siglo XVIII. La respuesta campesina a la detracción señorial y la lucha por el acceso a los recursos", Áreas (Estructura agraria y conflictividad), 15, (1993): 99-111. 
Pasados estos dos años, el comendador aportará 2.000 libras en moneda de oro o plata. Si los gastos son superiores, correrán a cargo del común de Torres de Segre ${ }^{31}$.

En el mismo cuadro 1 se reproducen las contribuciones a la Junta por el uso del agua en 1851, cuando la reforma agraria liberal ya ha avanzado significativamente. Se observa el mantenimiento de los censos que se pagaban en el antiguo régimen, el cambio de manos de algunas contribuciones -como las referidas a los hospitalarios de Torres de Segre o Alguaire, y de Corbins, aunque en este caso aún figura el antiguo titular-. Aparecen nuevos nombres de particulares. Se trata de concesiones a grandes propietarios burgueses que disponen de una cantidad importante de tierra o de algún medio de producción ${ }^{32}$, como puede deducirse de la cantidad anual a pagar, aunque no puede compararse con los censos antiguos, ya que estos no se han revalorizado con el tiempo.

\section{Problemas sanitarios en las huertas de Pinyana y Fontanet}

La crisis del siglo XVII había dejado a buena parte de la Cataluña occidental llana con limitados efectivos demográficos. La Guerra del Segadors (1640-1652) había impactado negativamente en las zonas afectadas por las batallas -Lleida y comarca-, hasta el punto que algunas poblaciones habían ido desapareciendo. Incluso Torrefarrera se despoblará temporalmente a pesar de tener una agricultura regada por la acequia de Pinyana ${ }^{33}$. La recuperación y expansión del siglo XVIII se caracteriza, a nivel territorial, por un aumento de la concentración demográfica en poblaciones

31 "Torres de Segre. Representació a la Religió sobre varios punts y en particular de las Herbas y sisena" (1804), ACA, SJJ, c.1711, Armario 19, legajo 2a; “Concòrdia feta y firmada per lo Ille. Sor. Fr. Dn. Nicolas de Armengol, Comdor de la Encomda de Torres de Segre de una parte, y el Ayuntamto y Particulares de la misma Villa de otra, ACA, SJJ, 1804, Armario 19, legajo 2b; "Capbreu de la Vila de Torres de Segre y son terme", ACA, SJJ, 1767, Armario 19, volumen 2.

32 El 9 de abril de 1850 la Junta de Cequiaje concede al Marqués de Alfarràs la facultad de construir un molino aceitero con dos muelas en la acequia de Noguera (Pinyana). Archivo de la Junta de Sequiatge de Lleida (AJSL), Actas de la Junta de 1850, A61-C.XIII.

33 "Cabbreu fet per lo Molt Illre Fra don Miquel Torrellas y de Sammanat, prior de Cathaluña del lloch y terma de torra Farrera", ACA, SJJ, 1659, Armario 11. 


\section{Mapa 3}

Población activa en la región de Lleida, 1721 y 1787

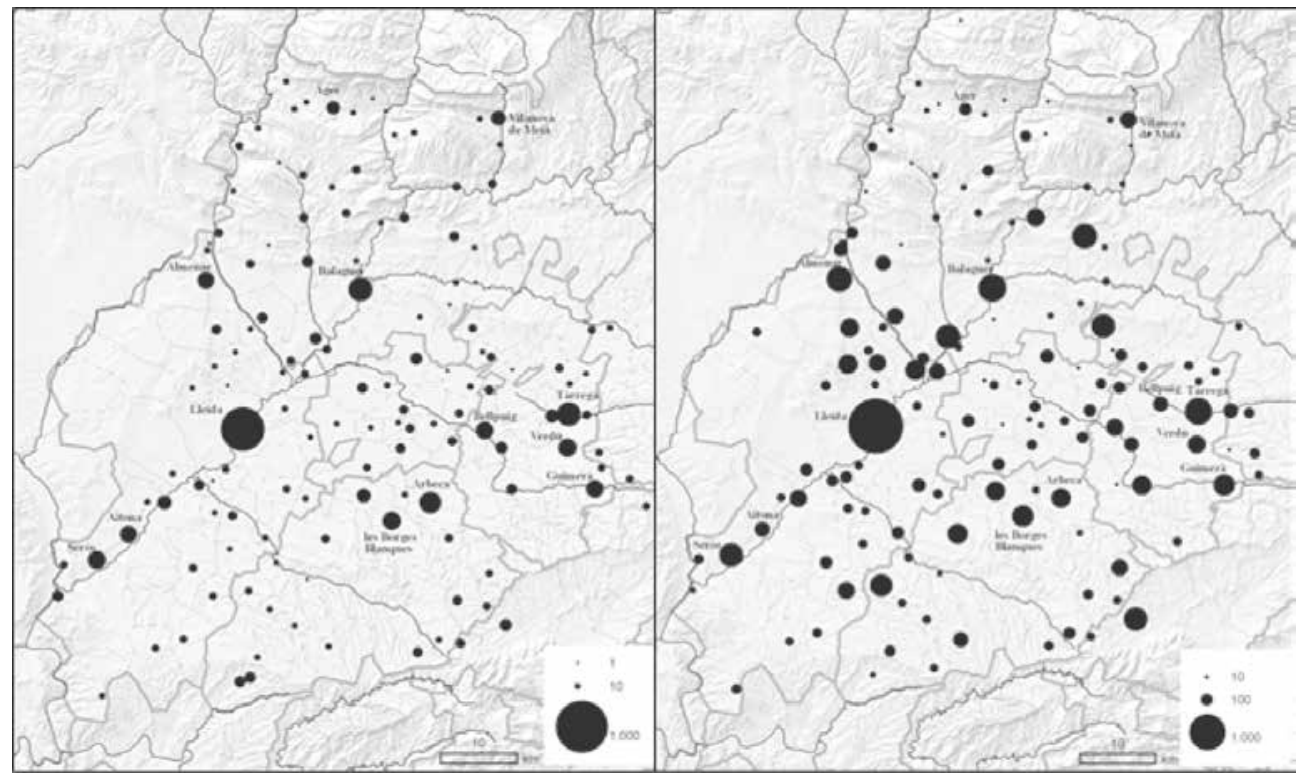

Fuente: "Censo de la población activa del Corregimiento de Lleida", 1721. Archivo Histórico de Lleida, Catastro, Caja 61, y Josep Iglésies (ed.), El cens del comte de Floridablanca, 1787.

Part de Catalunya, 2 vols., (Barcelona, Fundació Salvador Vives Casajuana, 1969).

próximas a ríos o acequias ${ }^{34}$. El mapa 3 muestra este hecho comparando los datos de población activa de un censo del Corregimiento de Lleida realizado en 1721 y los datos equivalentes del Censo de Floridablanca de 1787. Tras la Guerra de Sucesión, la recuperación de la agricultura en primer lugar y la posterior expansión de la superficie cultivada exigen que el campesinado tenga a punto y cuide de todo el sistema de acequias, zanjas y desagües. En una huerta tan dilatada como la de Lleida fue un problema de enorme importancia la prohibición realizada por la nueva dinastía borbónica de que se pudiesen edificar viviendas fuera de las murallas de la ciudad. A pesar de que un siglo y medio más tarde, a partir de 1861, se demolieron las murallas de Lleida y ya no existe la citada prohibición, no será sino hasta principios del siglo XX que, nuevamente, se construirán "torres", nombre que en Lleida reciben las casas labriegas o masos.

34 Enric Vicedo-Rius, Les terres de Lleida i el desenvolupament català del set-cents. Producció, propietat i renda (Barcelona: Crítica, 1991). 
Las cuestiones sanitarias recibieron una gran atención por parte de las autoridades locales en el siglo XVIII. Por ejemplo, el cultivo del arroz fue objeto de preocupación por parte de las autoridades del corregimiento de Lleida. La Real Audiencia de Barcelona pidió al ayuntamiento de Lleida que informase sobre la cuestión, también para los pueblos vecinos, como gestor que era de las aguas de Pinyana y Fontanet. En la respuesta, escrita el 16 de enero de 1726, el ayuntamiento informa de que en Lleida el cultivo está prohibido a diferencia de los demás pueblos próximos, en los que los promotores del cultivo y los campesinos que necesitan de estos ingresos, inciden en la salud pública. El ayuntamiento de Lleida es favorable a su prohibición total. Sobre las balsas de empozar y macerar el cáñamo se indica que se controlan pero se afirma que se aumentarán los controles por si hubiera habido alguna omisión. Sobre las avenidas del río Segre que inundan, recurrentemente, las parcelas de su margen izquierda, explica que mediante acciones se controlan las zonas encharcadas ${ }^{35}$.

La prohibición definitiva del cultivo del arroz se produjo en marzo de 1748. Marià Olives lo recuerda cien años después de su aprobación, afirmando que ha sido muy favorable para la salud de los payeses y recuerda que desde la siega en abril hasta la recolección en octubre los campos de arroz estaban sumergidos con un palmo de agua, foco de infecciones ${ }^{36}$. Además, en su Historia de Lérida hace referencia a las calenturas intermitentes que en verano y en otoño se producen debido a que los agricultores pasan las noches en el campo, en condiciones de humedad y poco salubres, dado que no disponen de viviendas ${ }^{37}$.

En la década de los años 1880 aparecen publicados dos estudios exhaustivos, de gran nivel académico, y ambos premiados: la topografía médica de Lleida de Luis Marlés de Cusa ${ }^{38}$ por la Real Academia de Medicina y Ciru-

35 "Satisfaciendo al orden de Su Exa y Rl Auda participando a este Ayuntamto...", informe enviado a don Hilario de Ribera, fiscal civil de la Real Audiencia., Lleida, 16 de enero de 1726, AML, Correspondencia, 1726-1727, fs. 18r-19r.

36 Marià Olives Roca, Colección de noticias o sea Memorias para formar la historia de la antiquísima y nobilísima ciudad de Lérida, Lleida, 1840. Texto manuscrito. Archivo Histórico del Institut d’Estudis Ilerdencs, Legado Pleyán de Porta. Las referencias sobre el cultivo del arroz en los folios 102r-102v.

37 Marià Olives Roca, Colección..., folio 97 r.

38 Luis Marlés de Cusa, Estudio médico topográfico y estadístico de Lérida, (Lleida: Establecimiento Tipográfico de la Casa de Misericordia de la Provincia de Lérida, 1882). 
gía de Barcelona, y el estudio sobre la huerta de Lleida de Antoni Blàvia por la Sociedad Económica de Amigos del País de la misma ${ }^{39}$.

Luis Marlés muestra su alegría por la prohibición del cultivo de arroz dadas las insuficientes condiciones higiénicas que caracterizan la ciudad y la huerta de Lleida. Se refiere, como hacía Olivés cuatro décadas antes, a las fiebres intermitentes derivadas de los establos y un mal sistema de cloacas en la ciudad, y de...

“... esos pudrideros de sustancias vegetales que se utilizan para los abonos de los campos y que en gran número existen en los alrededores de Lérida, ese mal suelo en el cauce del río que hace, que al bajar el nivel de las aguas deje charcos que vienen a formar pequeños pantanos, esos charcos de agua que en bastante número se encuentran en los contornos de la urbe, constituyen focos de mefitismo que, dirigiendo a esta sus efluvios constituyen las principales causas de las enfermedades típicas que, con poco trabajo pueden desaparecer, higienizándose así notablemente la urbe, si éstas, como creemos, son las causas ocasionales de las intermitentes" 40 .

Antoni Blàvia ${ }^{41}$, en su propuesta de colonización de la huerta de Lleida, afirma que en las zonas más próximas a la ciudad de Lleida, de uno a tres $\mathrm{km}$ de distancia, las tierras están bien cuidadas y drenadas. El problema principal es que, dada la práctica inexistencia de colonos que viven en la huerta, las más alejadas son focos de fiebres intermitentes y de paludismo para los pocos colonos que las habitan. Con la nueva población de la huerta se conseguiría mejorar estas problemáticas y hacer una agricultura más productiva.

39 Antoni Blàvia, "Colonización de la huerta de esta ciudad y medios más convenientes para mejorar la producción de su suelo", en Sociedad Económica de Amigos del País de Lérida, Solemne sesión celebrada el 12 de mayo de 1889 y memorias agraciadas en dicho acto (Lleida: Imprenta de José Pla y Pagés, 1889).

40 Antoni Blàvia, "Colonización de la huerta de..., 26.

41 Para las cuestiones que siguen, véase "Saneamiento de las partidas insalubres de nuestra huerta", en Antoni Blàvia, "Colonización de la huerta de...", 57-59. 
"Las partidas de Lipbia, Grealó, parte de la de Butsènit, Prats de Navés, Malgobern, los alrededores de Torrefarrera y Torreserona tocando a nuestro término, donde son abundantísimas las aguas o tienen pantanos, charcos, etc. son las que, en primer lugar, deben ocuparnos".

Estos problemas se resolverían a partir del siglo XX cuando la población comenzó de nuevo a construir "torres" y a vivir en la huerta en unas condiciones de vida superiores a las que tenía cuando vivía hacinada dentro de las murallas.

Otro problema importante será el de las filtraciones. Por ejemplo, Blàvia explica un problema reciente que contamina las aguas de la acequia de Fontanet:

"De pocos años a esta parte los agricultores de la fértil y famosa vega de Fontanet se quejan de que sus tierras, a pesar de los abonos, pierden su potencia productora, enfermando con frecuencia los que beben las aguas del riego. Débese esto indudablemente a la mezcla de las aguas del Regué de les Sogues o Salat con las de la acequia de Fontanet. Ya en una ocasión la junta de Cequiaje obligó a la Compañía del Canal a desviar la dirección del regué para que la mezcla de las aguas no se efectuara. Esto sería lo más conveniente, pero como la presa del agua de Vilanova de la Barca se obstruye fácilmente y el agua del Segre no entra por la mina, o entra en muy poca cantidad, de aquí que los mismos propietarios de Fontanet prefieran, antes de quedarse sin agua, regar con la del desagüe del canal o Regué de les Sogues".

En 1941, filtraciones procedentes del canal de Seròs -que se origina en Lleida y llega hasta la central eléctrica de Seròs, construida a principios de siglo por la Canadiense-, inundan las tierras regadas por la acequia de Fontanet.

"Es urgentísimo remediar y evitar el fenómeno producido, porque el espesor seco del terreno de cultivo ha quedado práctica- 
mente anulado y las raíces de las plantas, por superficiales que sean, quedan sumergidas en el agua, con lo que, ni los abonos, ni las bacterias fertilizadoras, producen sus efectos, a más de quedar francamente vulneradas todas las condiciones de vida vegetal en cuanto a las del terreno".

Se advierte también que si no se realizan las tareas de mantenimiento adecuadas y urgentes en el citado canal, las condiciones de salubridad empeorarán y no permitirán el ensanche de la ciudad hacia el margen izquierdo del río Segre ${ }^{42}$.

Retomando el tema del arroz, su cultivo ya no volverá a autorizarse hasta principios de la década de 1950, cuando las necesidades alimenticias durante la larga posguerra civil se traducía en permitir también este cultivo, siendo las principales zonas arroceras Lleida, Alcarràs y Torres de Segre. El $55 \%$ de los cultivadores dedican hasta 0,5 hectáreas ${ }^{43}$.

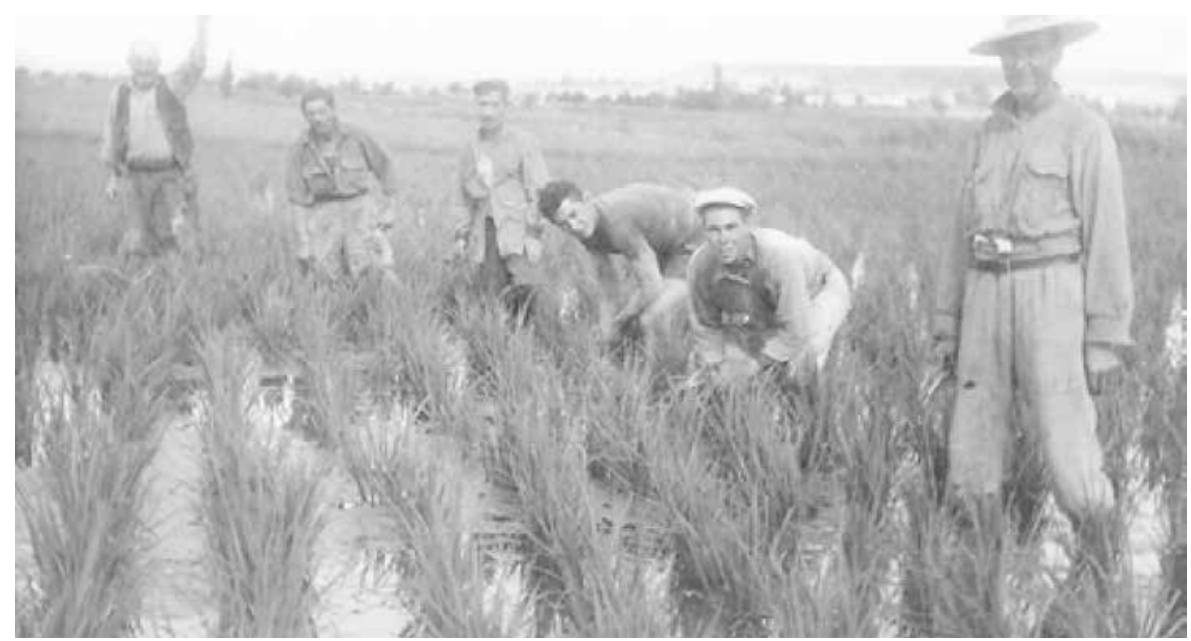

Aclarando el arroz en Vilanova de Segrià, en 1957

42 Informe capa freàtica horta Fontanet, 1941, AJSL, Projectes obres, 1962, segle XX, A.3-1ª núm. LV-BIS.

43 Enric Vicedo-Rius. "La comunitat central de regants del Canal de Pinyana i Sèquia de Fontanet: noves institucions i vells conflictes en els recs del segrià (anys cinquanta del segle XX)", en Terra, aigua, societat i conflicte a la Catalunya Occidental, Enric Vicedo-Rius (ed.) (Lleida: Pagès editors, 2000), 215-237. 


\section{El canal de Urgell. Del modelo comunitario de Pinyana y Fontanet A LA INICIATIVA PRIVADA EN El CANAL DE URGELL}

Los llanos de Urgell experimentaban los mismos déficits hídricos que la comarca de Lleida. Por todo ello, desde el siglo XIV, como mínimo, se plantea la necesidad de crear un canal de riego en el Urgell. Guillem Catà, que había diseñado la acequia de Manresa en la Cataluña central es contratado por el conde Jaume d'Urgell en 1346 para realizar unos primeros estudios para los riegos del Urgell. Diversos intentos y proyectos se suceden hasta que en 1852 el gobierno concede definitivamente la autorización para la construcción del canal a la sociedad Girona Hermanos, Clavé y Cía. de Barcelona, que en diciembre de 1853 constituyen la Sociedad Canal de Urgel $^{44}$.

Sobre el impacto del canal de Urgell en la demografía de la zona, Josep $\mathrm{M}^{\mathrm{a}}$ Ramon muestra que durante la construcción del mismo el impacto fue positivo, pero nada comparable con el "boom" del periodo 1877-1930 cuando los riegos van consolidándose progresivamente. Las décadas dramáticas fueron las de los años 1860 y 1870 cuando el canal entra en funcionamiento. El paludismo afectó gravemente a la zona que dispuso de más agua, salvándose aquellas áreas alejadas a las cuales aún llegaba poca, o bien términos que habían de esperar a la construcción del canal auxiliar ${ }^{45}$ para poder disponer de ella (Artesa de Lleida, Montoliu de Lleida, Puigverd de Lleida, Borges Blanques, Juneda, Torregrossa). En Linyola y el Poal, entre 1865-1869, murieron entre un tercio y la mitad de la población. En general, el paludismo afectó de manera más cruenta a la población infantil ${ }^{46}$.

44 Josep Maria Ramon, "La complicada gestació del Canal d'Urgell. Cinc-cents anys de projectes, fracassos i oposicions (1341-1854)", en Terra, aigua, societat i conflicte a la Catalunya Occidental, Vicedo-Rius, Enric, (Lleida: Pagès editors, 2000), 181-214.

45 El canal auxiliar fue autorizado en 1919 y entró en funcionamiento en 1932.

46 Josep Maria Ramon "Els problemes vinculats als primers regadius: el daltabaix demogràfic durant les dècades de 1860 i 1870", en L'agricultura de regadiu a la Catalunya contemporània: els canals d'Urgell, 1860-1960, memoria de doctorado (Barcelona: Universitat Pompeu Fabra, 2004), 242-254. Del mismo autor, Josep-Maria Ramon-Muñoz, "Cambio agrario, uso del suelo y regadío: el impacto del Canal de Urgell, 1860-1935”, Historia Agraria, Vol. 59 (2013): 43-94. 
En 1919 se propone la desecación del "Estany [estanque] d'Ivars" por parte de un grupo de propietarios que representaban los intereses de la propiedad. Se argumenta que es un gran charco foco de paludismo, como lo era el Estany de Vila-sana hasta que fue desecado. El Estany d'Ivars está ubicado en el de Vila-sana y en el de Ivars d'Urgell. El Sindicato General de Riegos del Canal de Urgell se opuso por el daño que podía generar en los riegos de verano, ya que el agua acumulada servía para hacerlos en unas 1.500 hectáreas. Se presentaron certificaciones por parte de los juzgados municipales para demostrar la falsedad del tema sanitario. Por ejemplo, entre 1910 y 1919 no hubo en Ivars d’Urgell, el pueblo más cercano al estanque, ninguna defunción por paludismo y solo tres por fiebre tifoidea ${ }^{47}$.

Hechas estas observaciones, el objeto de nuestro análisis es definir la naturaleza de este nuevo canal durante los 99 años de concesión privada en comparación con los canales de Pinyana y de Fontanet. Realidad bien diferente será la que se producirá a partir de la década de 1960 cuando los canales -el principal y el auxiliar- pasarán a manos de la Comunidad de Regantes.

\section{Cuadro 2}

Distribución de los cultivos (hectáreas) en la zona regada por el Canal de Urgel, 1880-1920

\begin{tabular}{|l|l|l|c|c|c|c|c|c|}
\hline & Campa & Viña & $\begin{array}{c}\text { Viña y } \\
\text { Olivo }\end{array}$ & Olivo & Alfalfa & Huerto & Yermo & Total \\
\hline 1880 & 26.507 & 7.605 & 8.445 & 5.502 & 1.259 & 150 & 7.886 & 57.353 \\
\hline 1890 & 25.881 & 7.808 & 9.046 & 6.095 & 2.387 & 240 & 6.044 & 57.502 \\
\hline 1900 & 28.818 & 2.844 & 11.606 & 6.558 & 3.989 & 264 & 4.057 & 58.136 \\
\hline 1905 & 27.344 & 3.912 & 12.132 & 5.868 & 6.000 & 235 & 3.454 & 58.946 \\
\hline 1910 & 24.939 & 3.359 & 14.047 & 7.297 & 6.495 & 206 & 3.444 & 59.787 \\
\hline 1915 & 21.655 & 3.178 & 17.049 & 6.757 & 7.652 & 224 & 3.404 & 59.919 \\
\hline 1920 & 24.374 & 2.635 & 16.693 & 6.848 & 6.588 & 216 & 2.684 & 60.039 \\
\hline
\end{tabular}

Fuente: "Canal de Urgel. Estadística de la superficie adherida...", en Estadístiques: població, superfícies, produccions (finals segle XIX, principis segle XX). Archivo del Canal de Urgell, Capítulo 9, artículo 4, grupo A-4.

47 Josep Rubió Cabecerán, Ivars d'Urgell i l’antic estany (Lleida-Cervelló: Editorial Dilagro, 1977). En otro contexto político, en 1950 se deseca el estanque, y recientemente está siendo recuperado. 
El proyecto de la Sociedad "Canal de Urgel” consistía fundamentalmente en dar riegos suficientes para garantizar que las cosechas y producciones de la trilogía mediterránea no se perdiesen por las duras condiciones del clima mediterráneo de tendencia continental. El mismo argumento que hemos visto en el proyecto de nuevos riegos para Almacelles a finales del siglo XVIII.

Veamos esta realidad a partir del cuadro 2. La viña experimenta una fuerte reducción, tras la filoxera que en la zona se expande a partir de 1895 y una limitada replantación en unos momentos en que la producción francesa y de otras zonas mediterráneas se ha recuperado. El olivar tiende a expandirse por la coyuntura favorable de las primeras décadas del siglo XX, como sucede con la combinación de viña y olivo con presencia mayoritaria de este último. La alfalfa es la gran protagonista, con un crecimiento del $400 \%$, mientras que el huerto, a pesar de un significativo aumento porcentual, solo dispone en 1920 de 216 hectáreas. Ello se debe a que en el Convenio de Madrid de 17 de febrero de 1862 -en el que se establecían las características del nuevo canal de riego- se determina que los huertos son para el consumo propio de sus familias, y consistirían en media porca si la tierra regada por el canal no supera los diez jornales. Para quienes dispongan de más de 300 jornales, el huerto ocupará el máximo de tres porcas ${ }^{48}$. La "Sociedad Canal de Urgel” percibirá la novena parte de la producción de las tierras adheridas al riego.

Las diferencias con los riegos de Pinyana y Fontanet son muy evidentes. En primer lugar, la titularidad. Frente a unos riegos en el Segrià que podemos calificar de públicos, el Canal de Urgell es una concesión privada. Se trata de una sociedad anónima cuyo objetivo, a pesar del interés que alguno de sus promotores pueda tener para mejorar la agricultura, era también la obtención de un beneficio. Recordando que una tierra de calidad mediana podía rendir ocho cuarteras de trigo que, a razón de doce cuartanes por cuartera, totalizan 96 cuartanes, el noveno serían 10,7 cuartanes, más de diez veces lo que se exigía habitualmente en los riegos de Pinyana y de Fontanet (un cuartán por jornal, como hemos visto). Además se había de

48 "Canal de Urgel, Sindicato General de Riegos. Circular. 20 de agosto de 1864", AML, Registro 1618/1868. Un jornal equivale a 0,44 ha. Cada jornal está dividido en doce porcas. 


\section{Cuadro 3}

Cultivos en el área regada por los canales de Urgel, 1941

\begin{tabular}{|c|c|c|c|}
\hline Cosecha & Hectáreas & Pesetas & pesetas/hectárea \\
\hline Trigo & 8.397 & 7.758 .828 & 924 \\
\hline Cebada & 8.838 & 5.727 .024 & 648 \\
\hline Avena & 1.797 & 808.650 & 450 \\
\hline Legumbres & 397 & 381.120 & 960 \\
\hline Paja & 19.429 & 12.143 .125 & 625 \\
\hline Alfalfa & 6.181 & 16.688 .700 & 2.700 \\
\hline Huertos & 723 & 1.446 .000 & 2.000 \\
\hline Almendras & & 2.600 .000 & 780 \\
\hline Vendimia & 3.000 & 2.340 .000 & 1.600 \\
\hline Judías & 1.000 & 1.600 .000 & 1.850 \\
\hline Maíz & 3.500 & 6.475 .000 & 120 \\
\hline Aceitunas & 8.463 & 1.015 .560 & 600 \\
\hline Mijo & 900 & 540.000 & 450 \\
\hline Calabazas & 260 & 117.000 & 320 \\
\hline Remolacha azucarera & 800 & 256.000 & 625 \\
\hline Remolacas forrajera & 250 & 156.250 & \\
\hline Cáñamo, lino, etc. & & 500.000 & \\
\hline Total & & 60.553 .257 & \\
\hline Fun “Cana de & & & \\
\hline
\end{tabular}

Fuente: "Canal de Urgel S.A: Secciones todas. Cosechas. Resumen de los productos obtenidos y valoración de los mismos en el ejercicio de 1941". Archivo del Canal de Urgell, Cap. VII-Art. XI-Grup C-N57.

pagar la cuota al sindicato de riegos para realizar las actividades de limpieza y mantenimiento que le eran propias. La extrema limitación de la superficie dedicada a la producción de hortalizas descartaba su comercialización en mercados como Barcelona, Lleida o Balaguer, y mediante la industria conservera, como sí sucedía en la huerta de Lleida durante el primer tercio del siglo XX.

Según el Libro de Cequiaje de la huerta de Lleida fechado en 17 de julio de $1937^{49}$, las acequias de Pinyana y Fontanet regaban tierras de 2.771 propietarios que disponían de 14.766 jornales [6448 ha] y huertos de 361

49 “Llibre de Sequiatge de 1937”, AJSL. 
propietarios que totalizaban 1013 jornales [442 ha]. Ni qué decir que más de cuatrocientas hectáreas de huertos podían satisfacer la demanda urbana y además generar un excedente que tenía en la industria conservera una salida rentable.

En el área regada por el canal de Urgell, los huertos y las legumbres tienen aún una presencia discreta en 1941, a pesar de que los primeros han aumentado significativamente en relación a 1920 (cuadro 2). La alfalfa mantiene una superficie similar a la de 1920 pero es el cultivo más productivo en términos monetarios, seguido de los huertos, el maíz y las judías.

Finalmente, el marco de acción era diferente: los riegos de Pinyana y Fontanet se organizaban en el marco de la comunidad campesina local, mientras que el canal de Urgell tenía un doble nivel: el sindicato particular, formado por diversos pueblos próximos, y el sindicato general formado por todos los sindicatos particulares. Desde este punto de vista, el payés de la zona regada por el canal de Urgell empezó pronto a considerar como ámbito directo de su actuación un espacio más amplio que el local.

\section{Cambios institucionales en las décadas de los AÑos 50 y 60}

Durante la segunda mitad del siglo XX se producen transformaciones muy relevantes en la titularidad y gestión de los riegos de Pinyana y Fontanet y de los canales de Urgell -el principal y el auxiliar-. Ambos acabarán siendo gestionados por comunidades de regantes recién creadas. En el caso de Pinyana y Fontanet ${ }^{50}$, entre el 17 de octubre de 1948 y el 14 de marzo de 1951 se debaten las ordenanzas de la Comunidad Central de Regantes. El 6 de junio de 1955 se aprueban las ordenanzas y siete años más tarde, el 6 de agosto de 1962, se registran los caudales a nombre de la comunidad. El 13 de abril de 1967 se transforma en Comunidad General de Pinyana y Fontanet hasta que el 16 de noviembre de 1990 se divide en dos, uno para cada sistema de riegos. La gestación de la Comunidad Central generó fuertes tensiones ya que los pueblos regantes del norte del Segrià se opo-

50 Enric Vicedo-Rius, "La comunitat central de regants del Canal de Pinyana...”. 
nían porque pensaban que perderían "derechos históricos". Tampoco, la ciudad de Lleida, como entidad central en la Junta de Cequiaje creada en el siglo XVIII, se mostró entusiasta inicialmente en el tema. Tras los intentos de registrar las aguas de Pinyana y Fontanet a nombre de la Junta, el 14 de febrero de 1948 una fuerte presión de la Confederación Hidrográfica del Ebro obliga a iniciar el proceso de creación de la Comunidad Central. Lleida, aliada con Alpicat y Alcarrás, dirigió la operación, garantizando el riego a Alcarràs -ubicado al final de la acequia de Pinyana-como miembro que era de la nueva comunidad, ante la oposición de los pueblos del norte que delegaron en unos pocos representantes que afirmaban que Alcarràs solo tenía derecho a las aguas sobrantes ${ }^{51}$.

En otras palabras, a pesar de que se mantienen las comunidades locales como base de la gestión de los riegos, la novedad que se produce es que ahora hay que establecer estrategias globales para toda la zona regada, quedando abolidos los privilegios históricos o prácticas no igualitarias. Por su parte, como hemos explicado, los pueblos del área de los canales de Urgell ya establecían estrategias comunes a nivel de sindicato particular de varios pueblos y términos, y participaban en el sindicato general. La novedad es que a partir de 1965 es la Comunidad General de Regantes de los Canales de Urgell la propietaria de los canales y, por tanto, son los regantes los sujetos activos de los riegos. Esta recuperación del canal no estuvo exento de lucha, ya que en noviembre de 1882 un decreto modificaba el Convenio de Madrid de 1862 según el cual la concesión era de 99 años. El decreto establecía la perpetuidad en la concesión, lo cual provocó una fuerte contestación por parte de los regantes consiguiendo que el gobierno suspendiese el decreto cinco años después ${ }^{52}$.

51 "En este momento don José Pociello Bardají, en todas las representaciones que ostenta manifiesta su disconformidad y su protesta por la elección de los vocales en representación del término final de riego y que son propietarios regantes del término de Alcarrás, por considerar que la zona que concierne a dicho término municipal no posee iguales derechos y prerrogativas que el resto de los usuarios, y sí solamente derecho al uso de aguas sobrantes. Don Francisco Trenc y don José María Bañeres, en las representaciones que ostentan, se adhieren a las manifestaciones del señor Pociello". "Libro de actas de la Comunidad Central de Regantes del Canal de Pinyana y Acequia de Fontanet", 17 juny 1951 a 2 juny 1966, f. 69r, AJSL.

52 Sobre la lucha contra la privatización del agua, véase José E. Castro, Léo Heller y María da P. Morais, coords., "Dossier: La lucha por el derecho al agua y las políticas públicas en América Latina", en Agua y Territorio, 2. 


\section{Conclusiones}

La creación y extensión de las superficies regadas era una condición necesaria para que la Cataluña occidental llana pudiera desarrollar su economía agraria desde la etapa medieval. Las acequias de Pinyana y Fontanet jugaron un papel clave. Con unos cequiajes muy reducidos y una gestión centralizada desde el Ayuntamiento de Lleida primero, la Junta de Cequiaje desde 1758 y las comunidades Central y General a partir de la segunda mitad del siglo XX, para los tema generales, y una descentralización que daba a las comunidades locales la posibilidad de una gestión más eficiente; este modelo público sigue la tradición andalusí que prima el riego por encima de la molienda señorial ${ }^{53}$.

El Canal de Urgell será una apuesta privada, con un cequiaje elevado, que hasta la década de 1960 tendrá como objetivo principal paliar los déficits hídricos de la zona que afectan, principalmente, a la trilogía mediterránea y a la creciente producción de alfalfa. Por ello, es tan limitada la superficie de huertos respecto a la superficie total, a diferencia de lo que ocurre en la huerta de Lleida. Durante el primer tercio del siglo XX, Lleida dispuso de una industria conservera que absorbía excedentes de los hortelanos.

Los problemas sanitarios generados por las deficiencias en la circulación de las aguas han existido en diversos momentos iniciales de las redes de riego, pero en el caso de Lleida la prohibición borbónica de construir viviendas en la huerta hará que algunas partidas estén mal trabajadas y drenadas, con problemas que se extenderán hasta principios del siglo XX, cuando se repoblará la huerta de Lleida y ello facilitará un mayor acondicionamiento del medio agrario, un mayor rendimiento y una mayor productividad del trabajo. El cultivo del arroz estuvo prohibido en esta zona durante todo este largo periodo. Otros temas, como el caso de la desecación del Estany

53 A partir de mediados del siglo XIX, en el marco del nuevo régimen liberal, fueron instalándose progresivamente otras actividades industriales y de servicios. Enric Vicedo e Ignasi Aldomà, "Las actividades industriales y de servicios mediante el uso de las aguas de los canales de Pinyana y de Urgell y de la acequia de Fontanet", en Book of the Congress on Industrial and Agricultural Canals. Porta i Casanellas, Jaume (Editor-in-Chief), (Lleida: Fundació Universitat de Lleida, 2014), 470-473. 
d'Ivars en la zona del canal de Urgell por motivos sanitarios, fueron muy debatidos por la población.

A partir de la segunda mitad del siglo XX, se produce un cambio en ambos sistemas: la creación de las comunidades de regantes, que serán las titulares de los riegos, y, en el caso del Canal de Urgell, ahora sin ningún tipo de restricción en relación a las especializaciones. Pronto el desarrollo de la fruta dulce dará un nuevo perfil a zonas tanto de los canales de Urgell como de Pinyana y Fontanet.

Fuera cual fuere el modelo, la gestión comunitaria de las acequias facilitará el desarrollo de una identidad colectiva por parte de las comunidades campesinas locales, aunque con tendencia a ampliar el ámbito de relación que cristalizará en las comunidades de regantes en la segunda mitad del siglo XX. Algunas resistencias a perder privilegios o prácticas históricas beneficiosas caracterizaron la creación de la Comunidad Central de Regantes de Pinyana y Fontanet en 1955.

\section{Bibliografía}

\section{Fuentes primarias}

\section{Archivos}

Archivo del Canal de Urgell (ACU).

Archivo de la Corona de Aragón (ACA).

Archivo de la Junta de Sequiatge de Lleida (AJSL).

Archivo Histórico del Institut d'Estudis Ilerdencs, Legado Pleyán de Porta. Archivo Municipal de Lleida (AML).

\section{Fuentes secundarias}

A.A.V.V. Historia de una tierra. Centenario del Canal de Aragón y Cataluña, 1906-2006. Binèfar: Ediciones 94-Comunidad, 2006.

Aldomà, Ignasi y Enric Vicedo. 'L'aprofitament històric de l'aigua a la Catalunya seca; una anàlisi a partir del patrimoni etnogràfic del terme de Torrebesses a la Vall Major (Segrià-Garrigues)", Estudis d'Història Agrària Vol. 23 (2012): 13-36. 
Blàvia, Antoni. "Colonización de la huerta de esta ciudad y medios más convenientes para mejorar la producción de su suelo”. En Sociedad Económica de Amigos del País de Lérida. Solemne sesión celebrada el 12 de mayo de 1889 y memorias agraciadas en dicho acto, pp. 49122. Lleida: Imprenta de José Pla y Pagés, 1889.

Castro, José E., Léo Heller y María da P. Morais, coords. "Dossier: La lucha por el derecho al agua y las políticas públicas en América Latina”. En Agua y Territorio, 2.

Elías, Francisco y Luis Ruiz. Agroclimatología de España. Madrid: Ministerio de Agricultura-Instituto Nacional de Investigaciones Agrarias, 1977.

Eritja, Xavier. "Dominicum comitis: estructuració feudal de l'horta urbana de Rufea (Lleida) durant la segona meitat del segle XII". En Terra, aigua, societat i conflictivitat a la Catalunya Occidental. Enric Vicedo-Rius(ed.). Lleida: Pagès editors, 2000, 25-46.

Garrabou Segura, Ramon y Josep-María Ramon-Muñoz. "Aigua, agricultura i regadiu a la Catalunya contemporània, 1800-2010”. Estudis d'Història Agrària Vol. 23 (2012): 27-57.

Gras i Esteva, Rafael. La Paheria de Lleida. Lleida: Ajuntament, 1911. Iglésies, Josep (ed.). El cens del comte de Floridablanca, 1787. Part de Catalunya, 2 vols. Barcelona: Fundació Salvador Vives Casajuana, 1969. Marlés de Cusa, Luis de. Estudio médico topográfico y estadístico de Lérida. Lleida: Establecimiento Tipográfico de la Casa de Misericordia de la Provincia de Lérida, 1882.

Olives Roca, Marià. Colección de noticias o sea Memorias para formar la historia de la antiquísima y nobilísima ciudad de Lérida, Lleida, 1840. Texto manuscrito. Legado Pleyán de Porta, Archivo Histórico, Institut d'Estudis Ilerdencs.

Ramon, Josep María. "La complicada gestació del Canal d’Urgell. Cinccents anys de projectes, fracassos i oposicions (1341-1854)". En Terra, aigua, societat i conflicte a la Catalunya Occidental. Enric Vicedo-Rius. Lleida: Pagès editors, 2000, 181-214.

Ramon, Josep María. L'agricultura de regadiu a la Catalunya contemporània: els canals d’Urgell, 1860-1960. Memoria de Doctorado. Barcelona: Universitat Pompeu Fabra, 2004. 
Ramon-Muñoz, Josep-María. “Cambio agrario, uso del suelo y regadío: el impacto del Canal de Urgell, 1860-1935”, Historia Agraria Vol. 59 (2013): 43-94.

Rubió Cabecerán, Josep. Ivars d’Urgell i l'antic estany. Lleida-Cervelló: Editorial Dilagro, 1977.

Serra, Eva. "Notes sobre els orígens i l'evolució de l'emfiteusi a Catalunya". Estudis d'Història Agrària Vol. 7 (1983): 127-138.

Sol, Romà y Carme Torres. Historia de un Canal, 1147-1974, Lleida: Autoedición, 1974.

Solé Sabarís, Lluís (dir.). Geografía de Catalunya, vol. 1. Barcelona: AEDOS, 1958.

Vicedo, Enric, Jaume Boixadera y José Ramón Olarieta. "Sistema hidráulico, organización de los riegos y usos del agua en la huerta de Lleida (1830-1950)". En El agua en los sistemas agrarios. Ramón Garrabou y José Manuel Naredo (coords.). Madrid: Argentaria/ Visor distribuciones, 1999, 225-254.

Vicedo-Rius, Enric. Les terres de Lleida i el desenvolupament català del set-cents. Producció, propietat i renda. Barcelona: Crítica, 1991.

Vicedo-Rius, Enric. "La conflictividad en las Terres de Lleida en el siglo XVIII. La respuesta campesina a la detracción señorial y la lucha por el acceso a los recursos", Áreas (Estructura agraria y conflictividad) Vol. 15 (1993): 99-111.

Vicedo-Rius, Enric. "La comunitat central de regants del Canal de Pinyana i Sèquia de Fontanet: noves institucions i vells conflictes en els recs del segrià (anys cinquanta del segle XX)". En Terra, aigua, societat $\mathrm{i}$ conflicte a la Catalunya Occidental. Enric Vicedo-Rius (ed.). Lleida: Pagès editors, 2000, 215-237.

Vicedo-Rius, Enric. "Mercado y precios. El almudí de Lérida, 1700-1833”. Historia Agraria Vol. 45 (2008): 53-88.

Vicedo-Rius, Enric. "La colonització rural a la catalunya occidental. Almacelles, 1750-1830”. En Jornades Internacionals d'Urbanisme i Arquitectura de la Il·lustració. Almacelles-Lleida: Ajuntament d'Almacelles-Pagès Editors, 2009, 17-30.

Vicedo-Rius, Enric (dir.). Els canals de Pinyana i Fontanet. L'aigua com a factor transformador de la regió de Lleida. Lleida: Pagès editors, 2006. 
Vicedo, Enric e Ignasi Aldomà. "Las actividades industriales y de servicios mediante el uso de las aguas de los canales de Pinyana y de Urgell y de la acequia de Fontanet", En Book of the Congress on Industrial and Agricultural Canals. Jaume Porta i Casanellas (Editor-in-Chief). Lleida: Fundació Universitat de Lleida, 2014, 470-473.

Vilar, Pierre. Catalunya dins l'Espanya moderna, v. 3. Barcelona: Edicions 62, 1966.

Para citar este artículo: Vicedo-Rius, Enric. "Riegos históricos y riegos contemporáneos en la Cataluña occidental llana. El agua y el desarrollo económico y cultural (1750-1950)", Historia Caribe Vol. X No. 26 (Enero-Junio 2015): 19-52. DOI: http://dx.doi.org/10.15648/hc.26.2015.2 